\title{
Rancang Bangun Prototype Pengering Padi Otomatis Berbasis Mikrokontroler AT89S52
}

\author{
Teguh Hidayat Iskandar Alam \\ Fakultas Teknik, Program Studi Teknik Informatika, \\ Universitas Muhammadiyah Sorong \\ J1. Pendidikan No.27, Kelurahan Klabulu, Distrik Malaimsimsa, \\ Kota Sorong - Papua Barat \\ Webesite: www.um-sorong.ac.id \\ E-mail: teguhhidhayat@gmail.com
}

\section{Abstrak}

Pengeringan padi pasca panen hingga saat ini dilakukan petani dengan metode tradisional yaitu menebarkan dan meratakan padi di bawah sinar matahari dengan tujuan mengurangi kelembaban dan menghindari kemungkinan berkembang biaknya jamur dan bakteri, serta mempermudah pengelupasan kulit padi. Proses ini memakan waktu 1 minggu agar padi yang dihasilkan berkualitas bergantung pada tingkat kecerahan cuaca.

Prototype mesin pengering padi berbasis mikrokontroler AT89S52 ini dirancang dari segi hardware: mekanisme kelistrikan dan desain mekanik, dan software: perancangan program otomatis dengan tujuan untuk membantu menghemat tenaga petani juga mempersingkat waktu pengeringan padi karena seluruh proses dikerjakan secara otomatis oleh sistem.

Hasil uji coba proses pengeringan dengan prototype pengering padi otomatis menghasilkan kualitas beras yang terjaga sesuai dengan standar dan mendekati kondisi kelembaban yang sesuai dengan beras normal.

Kata kunci : Pengering padi, AT89S52, Sensor suhu dan kelembaban SHT-11

\section{PENDAHULUAN}

Masalah yang sering dihadapi petani adalah bakteri dan jamur yang bertumbuh, hama dan kualitas padi yang kurang baik akibat lembabnya padi yang disimpan didalam gudang karena proses pengeringan padi yang kurang sempurna. Hal tersebut disebabkan oleh terhambatnya proses pengeringan pasca panen dikarenakan cuaca yang kurang mendukung. Petani sangat memanfaatkan tingkat kecerahan matahari untuk menjemur padi dalam proses pengeringan dan dilakukan kurang lebih selama satu minggu untuk mendapatkan hasil pengeringan yang sesuai standar dan berkualitas baik.

Oleh karena itu perlu adanya suatu prototype mesin yang dapat dimanfaatkan oleh petani untuk melakukan proses pengeringan pasca panen untuk menghindari permasalahan yang terjadi diatas dengan tujuan menghemat waktu dan tenaga petani, dapat dilakukan dalam kondisi cuaca apapun dan kapanpun sehingga petani tidak perlu lagi bergantung penuh pada tingkat kecerahan cuaca karena seluruh proses pengeringan dilakukan oleh sistem secara otomatis.

\section{LANDASAN TEORI}

\subsection{Perancangan Perangkat Keras}

\subsubsection{Mikrokontroler AT89S52}

Fungsi mikrokontroler pada prototype ini yaitu sebagai pusat pengendali utama dari sistem secara keseluruhan. Device ini bekerja selayaknya otak yang memberikan perintah pada seluruh hardware sesuai dengan kegunaanya secara otomatis.

Inputan mikrokontroler diterima dari sensor SHT-11 danmemberikanoutputuntukmengaktifkan 
relay motor AC, heater, blower, exhaust fan, buzzer sesuai dengan waktu yang disetting pada program.

Mikrokontroler AT89S52 memiliki 32 buah pin $\mathrm{I} / \mathrm{O}$, dimana yang terpakai sebanyak 2 pin sebagai input dan output sekaligus dan 17 pin sebagai output.

\subsubsection{Modul Relay, Motor AC, Heater, Blower, dan Exhaust fan}

Modul relay pada rangkaian ini berfungsi sebagai jembatan yang menghubungkan tegangan AC 220 Volt dengan peralatan elektronika. Modul relay ini digunakan untuk mengaktifkan heater, menggerakkan motor dan blower peniup serta penyedot. Pada modul relay ini terdapat 4 buah relay yang mewakili masing-masing channel.

\subsubsection{Sensor SHT-11}

Sensor SHT-11 adalah sensor suhu dan kelembaban yang berada di dalam 1 IC. Sensor ini memiliki keluaran berupa sinyal digital sesuai dengan perintah yang diberikan olehmikrokontroler. Keakurasian dari sensor ini $\pm 3,5 \%$ untuk akurasi kelembaban dan $\pm 0,5^{\circ} \mathrm{C} @ 25^{\circ} \mathrm{C}$ untuk akurasi suhu.

Adapun spesifikasi hardware sebagai berikut:

1. $-40^{\circ} \mathrm{C}$ hingga $123,8^{\circ} \mathrm{C}$.

2. Akurasi suhu $\pm 0,5^{\circ} \mathrm{C}$ pada $25^{\circ} \mathrm{C}$.

3. Range Kelembaban $0-100 \%$

4. Akurasi RH absolut $+3,5 \%$

5. Faktor bentuk 8 pin DIP - 0,6 "

6. Konsumsi daya rendah (tipikal 30uW)

7. Tegangan supply 5 VDC

Sensor ini memiliki 8 pin namun pin yang digunakan hanya 4 pin yaitu:

1. Pin 1

Pin ini digunakan untuk transimisi data input maupun output secara serial.

2. Pin 3

Pin ini digunakan sebagai clock generator untuk komunikasi data.

3. Pin 4

Pin ini digunakan sebagai GND.
4. $\quad$ Pin 8

Pin ini digunakan sebagai VCC.

Sensor ini berfungsi sebagai pembaca temperatur dan kelembaban ruangan. Sensor ini menggunakan jalur data bidirectional sehingga di dalam penggunaanya dapat menghemat banyak sekali pengalokasian pin mikrokontroler, karena sensor ini hanya menggunakan 2 pin saja yang berfungsi sebagai jalur data dan jalur clock. Rangkaian sensor ini memiliki skematik rangkaian seperti pada gambar 1 .

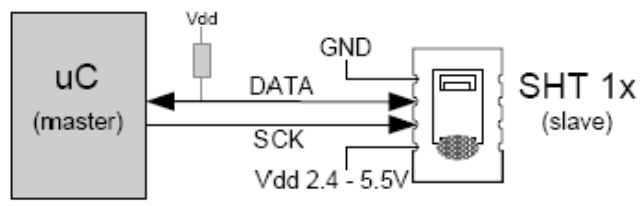

Gambar 1 Skematik rangkaian SHT-11

Pengoperasian sensor ini melalui sinyal yang diprogram secara manual. Untuk memulai setiap transmisi dibutuhkan transmission reset yang diikuti oleh transmission start sequence yang dapat dilihat pada gambar 2 dan 3 .

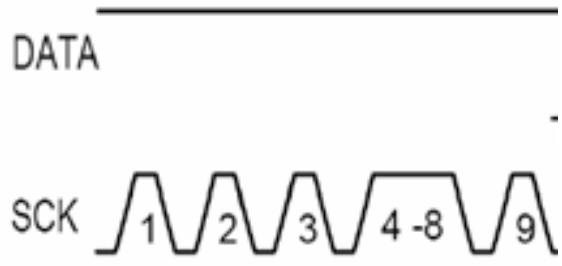

Gambar 2 Transmission reset

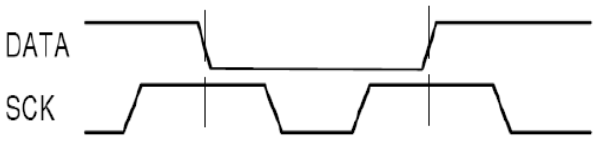

Gambar 3 Transmission start

Pada sensor ini terdapat beberapa perintah yang dapat dijalankan seperti tampak pada tabel 1, dan beberapa register untuk setting yang lebih lanjut, seperti yang ada pada tabel 2 . 
Tabel 1 Tabel perintah pada SHT-11

\begin{tabular}{|l|l|}
\hline Command & Code \\
\hline \hline Reserved & $0000 \mathrm{x}$ \\
\hline Measure Temperature & 00011 \\
\hline Measure Humidity & 00101 \\
\hline Read Status Register & 00111 \\
\hline Write Status Register & 00110 \\
\hline Reserved & $0101 \mathrm{x}-1110 \mathrm{x}$ \\
\hline $\begin{array}{l}\text { Soft reset, resets the interface, clears the } \\
\text { status register to default values } \\
\text { wait minimum 11ms before next command }\end{array}$ & 11110 \\
\hline
\end{tabular}

Tabel 2 Tabel register status pada SHT-11

\begin{tabular}{|c|c|c|c|c|}
\hline Bit & Type & Description & & fault \\
\hline 7 & & reserved & 0 & \\
\hline 6 & $\bar{R}$ & $\begin{array}{l}\text { End of Battery (low voltage detection) } \\
\text { ' } O \text { ' for Vdd }>2.47 \\
\text { ' } 1 \text { ' for } V d d<2.47\end{array}$ & $x$ & $\begin{array}{l}\text { No default value, } \\
\text { bit is only } \\
\text { updated after a } \\
\text { measurement }\end{array}$ \\
\hline 5 & & reserved & 0 & \\
\hline 4 & & reserved & 0 & \\
\hline 3 & & For Testing only, do not use & 0 & \\
\hline 2 & $R / W$ & Heater & 0 & off \\
\hline 1 & $\mathrm{R} / \mathrm{W}$ & no reload from OTP & 0 & reload \\
\hline 0 & R/W & $\begin{array}{l}1^{\prime}=8 \mathrm{bit} R H / 12 \mathrm{bit} \text { Temperature resolution } \\
\mathrm{O}^{\prime}=12 \mathrm{bit} \mathrm{RH} / 14 \mathrm{bit} \text { Temperature resolution }\end{array}$ & 0 & $\begin{array}{l}\text { 12bit RH } \\
\text { 14bit Temp. }\end{array}$ \\
\hline
\end{tabular}

Pada pengukuran suhu maupun kelembaban, mikrokontroler hanya meminta dengan memberikan alamat SHT-11, yaitu "000", kemudian diikuti dengan perintah yang diinginkan. Sebagai contoh apabila ingin mengukur kelembaban relatif maka mikrokontroler mengirimkan "000" yang diikuti oleh "000101".

Kemudian mikrokontroler menunggu hasil pengukuran selama waktu yang dibutuhkan. Lama waktu yang dibutuhkan untuk setiap pengukuran bervariasi tergantung resolusi pengukuran yang diminta.

Untuk resolusi 8 bit membutuhkan waktu 11 ms, sedangkan untuk resolusi 12 bit membutuhkan waktu $55 \mathrm{~ms}$, dan untuk resolusi 14 bit membutuhkan waktu hingga $210 \mathrm{~ms}$. Semakin tinggi resolusi, semakin akurat pula pengukuran yang dihasilkan. Pengukuran selesai ditandai dengan SHT-11 meLOW-kan jalur data.

[Dimas-Lucky, 2009: 30]

\subsubsection{Kelembaban Relatif Pengeringan}

Kelembaban relatif di dalam pengeringan sangat penting diperhatikan melihat kandungan air yang berada dalam padi saat dipanen masih cukup besar yaitu sekitar 25\% bahkan lebih. Proses pemanasan dengan heater sangat erat hubungannya dengan kelembaban padi. Apabila suhu semakin tinggi di dalam mesin pengering maka kelembaban akan semakin menurun begitupun sebaliknya.

Kelembaban yang baik untuk padi berkisar antara 13\%-14\% dimana kelembaban ini akan diperoleh dalam suhu yang tepat pada proses pengeringan. Suhu pada mesin haruslah konstan dan diatur agar kadar air di dalam padi semakin berkurang. Hal ini bertujuan untuk mendapatkan hasil beras yang baik. Ada dua hal yang harus dihindari dalam proses pengeringan padi yaitu:

Pengaruh kelembaban terlalu tinggi:

1. Padi akan lembab dan sulit untuk menguap

2. Pertumbuhan hama padi serta jamur semakin cepat

3. Menurunkan kualitas beras setelah digiling

4. Pengaruh kelembaban terlalu rendah:

5. Padi akan menjadi sangat kering dan retak

6. Saat dilakukan penggilingan maka padi akan pecah-pecah dan retak

7. Beras akan menjadi sangat keras dan tidak utuh secara fisik yang mengakibatkan penurunan kualitas dari beras tersebut.

[Noble - Andrizal, 2003: 8]

Suhu ruangan yang dipakai dalam proses pengeringan dengan menggunakan mesin pengering padi ini adalah antara $53^{\circ}$ Celcius sampai dengan $54^{\circ}$ Celcius. Temperatur ini harus dipertahankan agar kadar air yang terdapat dalam padi akan terus berkurang sehingga bisa didapatkan kelembaban ideal padi yaitu kurang lebih antara 13\% sampai dengan $14 \%$. Sehingga padi tidak mudah retak dan juga tidak mengandung kadar air yang berlebihan. 
Untuk mencapai suhu tersebut maka dalam mesin pengering ini diberikanheater sebagai pemanas untuk menjaga kestabilan suhu dalam proses pengeringan.

\section{PERANCANGAN PERANGKAT LUNAK}

Pemrograman yang digunakan sebagai otomatisasi sistem adalah pemrograman "C" yang dicompile menggunakan aplikasi Franklin ProView32 sehingga menghasilkan file .HEX yang akan dimasukkan ke dalam mikrokontroler melalui aplikasi ISP Programmer.

\subsection{Proses Cek Suhu}

Pada proses ini mikrokontroler melakukan pembacaan suhu, dimulai darimenulis alamat sensor dan diikuti oleh perintah yang ingin dijalankan. Diagram alirnya dapat dilihat pada gambar 4 .

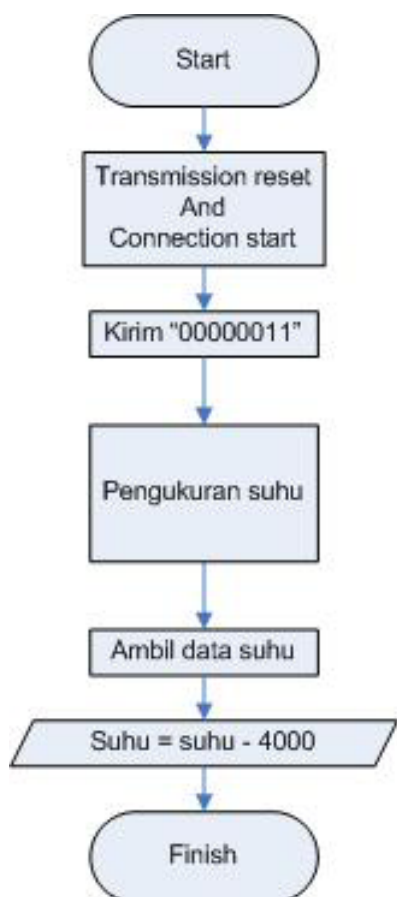

Gambar 4 Diagram alir pembacaan suhu

\subsection{Proses Cek Kelembaban}

Pada proses ini mikrokontroler melakukan pembacaan suhu, dimulai darimenulis alamat sensor dan diikuti oleh perintah yang ingin dijalankan. Diagram alirnya dapat dilihat pada gambar 5 .

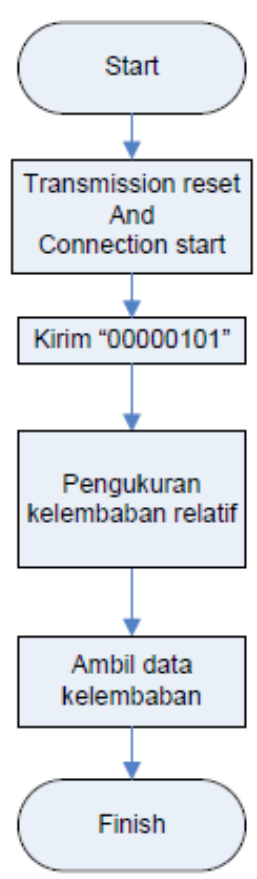

Gambar 5 Diagram alir cek kelembaban

\subsubsection{Blower}

Blower digunakan sebagai pengatur sirkulasi udara dan penjaga kestabilan kelembaban di dalam mesin pengering padi agar udara dan kelembaban di dalam mesin memiliki sirkulasi yg tepat dan blower juga memiliki fungsi lainnya yaitu sebagai exhaust fan.

\subsubsection{Buzzer}

Buzzer digunakan sebagai indikator pada mesin pengering padi ini. Buzzer akan berfungsi saat kondisi pada program yang dibuat telah terpenuhi. Rangkaian penggerak buzzer menggunakan transistor PNP. Transistor berfungsi sebagai saklar, transistor bekerja bila basis mendapat tegangan yang rendah (aktif low). Pemilihan penggerak buzzer aktiflow disesuaikan dengan mikrokontroler, saat mikrokontroler aktif maka semua port dalam keadaan tinggi (high). Dengan aktif low maka saat reset tidak adanya bunyi yang dihasilkan buzzer. 


\subsubsection{LCD $16 \times 2$}

LCD $16 \times 2$ digunakan sebagai tampilan dari mikrokontroler. LCD memiliki 16 pin dengan informasi sebagai berikut:

Tabel 3 Deskripsi pin LCD

\begin{tabular}{|c|l|}
\hline Pin & \multicolumn{1}{|c|}{ Deskripsi } \\
\hline 1 & VCC \\
\hline 2 & GND \\
\hline 3 & Tegangan kontras LCD \\
\hline & $\begin{array}{l}\text { Register select, 0 = Register } \\
\text { Command, 1 = Register Data }\end{array}$ \\
\hline 5 & 1 = Read, 0 = Write \\
\hline 6 & Enable Clock LCD \\
\hline 7 & Data Bus 0 \\
\hline 8 & Data Bus 1 \\
\hline 9 & Data Bus 2 \\
\hline 10 & Data Bus 3 \\
\hline 11 & Data Bus 4 \\
\hline 12 & Data Bus 5 \\
\hline 13 & Data Bus 6 \\
\hline 14 & Data Bus 7 \\
\hline 15 & Tegangan positif backlight \\
\hline 16 & Tegangan negatif backlight \\
\hline
\end{tabular}

Interface LCD merupakan sebuah parallel bus, di mana hal ini sangat memudahkan dan sangat cepat dalam pembacaan dan penulisan data dari atau ke LCD. Kode ASCII yang ditampilkan sepanjang 8 bit dikirim ke LCD secara 4 atau 8 bit pada satu waktu. LCD dapat ditunjukkan seperti pada Gambar 6.

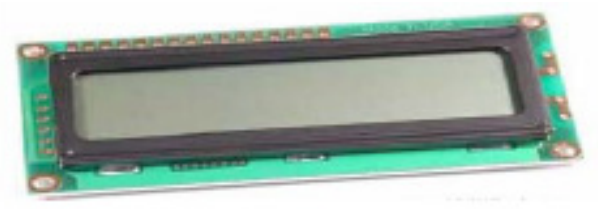

Gambar 6 Interface Modul LCD $16 \times 2$

Display karakter pada LCD diatur oleh pin EN, RS dan RW sebagai berikut:
1. Jalur EN dinamakan Enable. Jalur ini digunakan untuk memberitahu LCD bahwa anda sedang mengirimkan sebuah data. Untuk mengirimkan data ke LCD, maka melalui program EN harus dibuat logika low "0" dan set pada dua jalur kontrol yang lain RS dan RW. Ketika dua jalur yang lain telah siap, set EN dengan logika "1" dan tunggu untuk sejumlah waktu tertentu (sesuai dengan datasheet dari LCD tersebut) dan berikutnya set EN ke logika low " 0 " lagi.

2. Jalur RS adalah jalur Register Select. Ketika RS berlogika low "0", data akan dianggap sebagi sebua perintah atau instruksi khusus (seperti clear screen, posisi kursor dll). Ketika RS berlogika high "1", data yang dikirim adalah data text yang akan ditampilkan pada display LCD. Sebagai contoh, untuk menampilkan huruf "T" pada layar LCD maka RS harus diset logika high " 1 ".

3. Jalur RW adalah jalur kontrol Read/ Write. Ketika RW berlogika low (0), maka informasi pada bus data akan dituliskan pada layar LCD. Ketika RW berlogika high "1", maka program akan melakukan pembacaan memori dari LCD. Sedangkan pada aplikasi umum pin RW selalu diberi logika low "0". Untuk konfigurasi dari Pin LCD dapat dilihat pada Tabel 4

Tabel 4 Pin dan fungsinya pada $L C D$

\begin{tabular}{|c|c|}
\hline Pin & Fungsi \\
\hline 1 & Ground \\
\hline 2 & VCC \\
\hline 3 & Pengatur Kontras \\
\hline 4 & "RS" Instruction/Register Select \\
\hline 5 & "RW" Read/Write LCD Registers \\
\hline 6 & "EN" Enable clock \\
\hline $7-14$ & Data I/O Pins \\
\hline
\end{tabular}

(Dimas-Lucky, 2009: 36) 


\subsubsection{Motor AC}

Berdasarkan karakteristik dari arus listrik yang mengalir, motor AC (Alternating Current, Arus Bolak-balik) terdiri dari 2 jenis, yaitu:

1. Motor listrik AC / arus bolak-balik 1 fasa

2. Motor listrik AC / arus bolak-balik 3 fasa

Pembahasan dalam artikel kali ini di titik beratkan pada motor listrik AC 1 fasa, yaitu motor kapasitor

Motor AC satu fasa berbeda cara kerjanya dengan motor AC tiga fasa, dimana pada motor AC tiga fasa untuk belitan statornya terdapat tiga belitan yang menghasilkan medan putar dan pada rotor sangkar terjadi induksi dan interaksi torsi yang menghasilkan putaran. Sedangkan pada motor satu fasa memiliki dua belitan stator, yaitu belitan fasa utama (belitan U1-U2) dan belitan fasa bantu

\subsubsection{Tubular Heater}

Adalah jenis pemanas elektrik yang paling umum dan merupakan tipe dasar untuk membuat elemen pemanas lain ( cast-in, immersion, finned, radiant ). Tubular heater memiliki banyak kegunaan, bentuk, dan tipe pipa. Tipe pipa yang tersedia: - Titanium - Incoloy $(825,800)$ - Stainless Steel (seamless, welded) -Tembaga. Tubular heater kegunaanya adalah untuk memanaskan zat padat dan zat cair.

1. Zat padat: direkatkan pada dies, moulds, heat sealing tools, dll.

2. Zat cair: air, minyak, plating, aspal, garam, wax, parafin, dll.

\subsection{Metode}

\subsubsection{Tahap pertama}

Perancangan diawali dengan melakukan pra penelitian dan pra uji coba yaitu melakukan wawancara pada para petani mengenai lama waktu, tata cara dan proses pengeringan padi secara konvensional setelah panen.

Kemudian mengambil sampel padi pasca panen dan sampel padi hasil pengeringan petani secara konvensional untuk di uji coba pada laboratorium bahan pangan agar diketahui kadar kelembaban guna proses penyesuaian standar kelembaban pada padi hasil uji coba dengan prototype pengering padi.

\subsubsection{Tahap kedua}

Mendesain perangkat keras yaitu mekanisme kelistrikan dan desain mekanik yang akan digunakan serta mendesain perangkat lunak yaitu perancangan program otomatisasi sistem.

\subsubsection{Tahap ketiga}

Melakukan uji coba padi pasca panen pada prototype untuk melihat tingkat kesalahan dan error dan direvisi dan dicocokkan dengan standar kelembaban hasil uji coba laboratorium bahan pangan untuk disesuaikan pada hardware dan software sehingga mendapatkan hasil yang sinkron dengan standar kelembaban beras normal.

Padi hasil proses pengeringan prototype pengering padi tersebut kemudian diuji coba kembali pada laboratorium bahan pangan untuk dicocokan dengan hasil pengeringan secara konvensional dan juga mencocokan kualitas beras dari segi standar kelembaban yang berlaku pada beras normal yaitu sebesar $14 \%$.

Secara garis besar keseluruhan sistem pada prototype digambarkan sesuai dengan blok diagram pada gambar 6

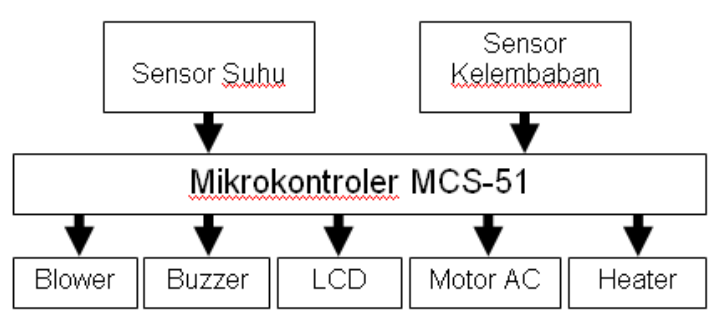

Gambar 6 Blok diagram sistem keseluruhan

serta alur flowchart uji coba prototype pengering padi pada gambar 7 . 


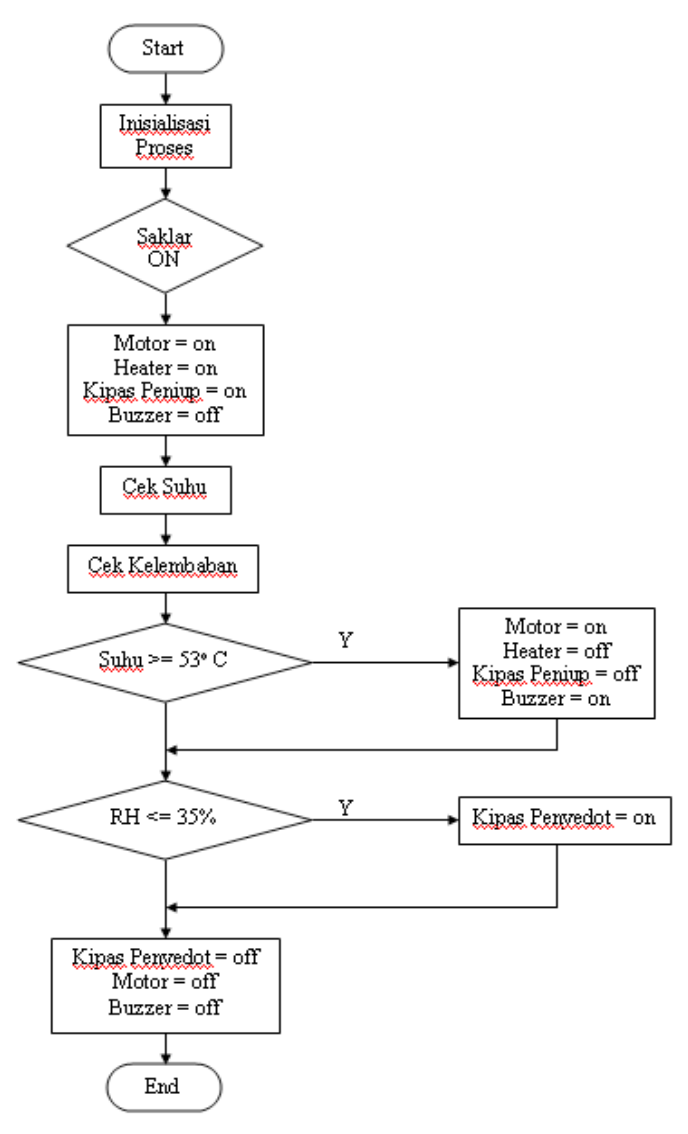

Gambar 7 Flowchart uji coba prototype pengerin padi

Berikut ini merupakan spesifikasi dari prototype pengering padi:

1. Alatinidioperasikandenganmenggunakan tombol.

2. Terdapat pemanas ruangan berupa heater 300 watt 220 VAC.

3. Terdapat blower sebagai peniup heater dan exhaust fan sebagai pengatur sirkulasi udara.

4. Dilengkapi dengan motor AC sebagai pemutar silinder mesin pengering padi.

5. Selama proses pengeringan padi, suhu yang dibutuhkan adalah berkisar antara $53^{\circ} \mathrm{C}-54^{\circ} \mathrm{C}$ dengan kelembaban antara $35 \%$ - 36\%, hal ini dilakukan dengan maksud untuk mendapatkan padi dengan hasil yang baik yaitu sekitar 14\%, agar padi tidak terlalu kering dan juga tidak terlalu mengandung banyak kadar air yang mengakibatkan tingkat kelembaban menjadi tinggi.

\section{HASIL UJI DAN PEMBAHASAN}

\subsection{Pengujian Sistem}

\subsubsection{Pengujian LCD}

Pengujian ini dilakukan untuk mengecek pemberi informasi yaitu LCD kepada para pengguna dari apa yang telah didapat dari proses pengeringan otomatis oleh sistem. Hasil tampilan dari pengujian ini dapat dilihat pada gambar 8 .

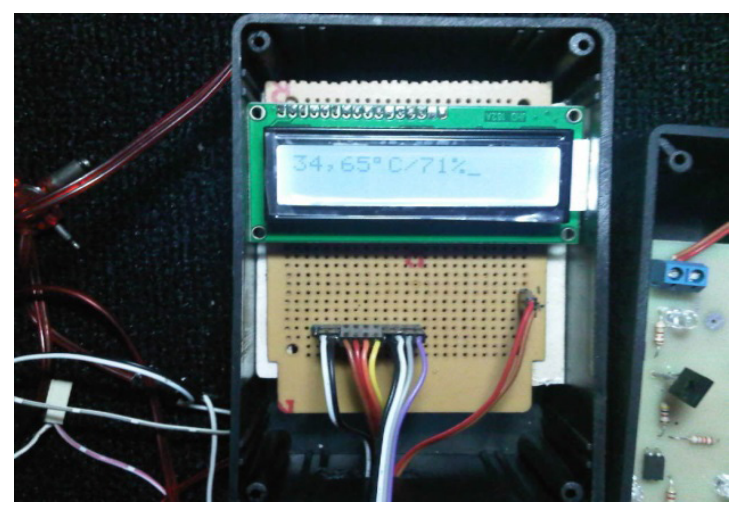

Gambar 8 Hasil pembacaan pada LCD

\subsubsection{Pengujian SHT-11}

Pengujian ini dilakukan pada tabung ruang mesin pengering ketika mesin ini diuji coba. Hasil pengukuran suhu dan kelembaban ruangan dapat dilihat pada tabel 3. Sensor diuji dengan mencocokkan nilai pada display LCD dengan termometer ruangan dan juga termometer badan.

Seluruh program uji temperatur maupun kelembaban menggunakan program uji terlampir. Mula-mula secara manual kita berikan inputan berupa panas serta kelembaban, kemudian sensor mengirimkan data tersebut pada mikrokontroler yang kemudian mengolah pada program yang didownload untuk memberikan output kepada rangkaian yang dituju. Hasil yang diperoleh untuk termometer ruangan dan badan dibulatkan nilainya 
sehingga perbandingan dengan sensor SHT-11 kurang lebih dapat terlihat. Untuk pengambilan data dari sensor SHT-11 dan termometer kami mengambil data per 20 detik dengan monitoring menggunakan stopwatch.

Tabel 5 Pengujian perbandingan SHT-11 dan termometer

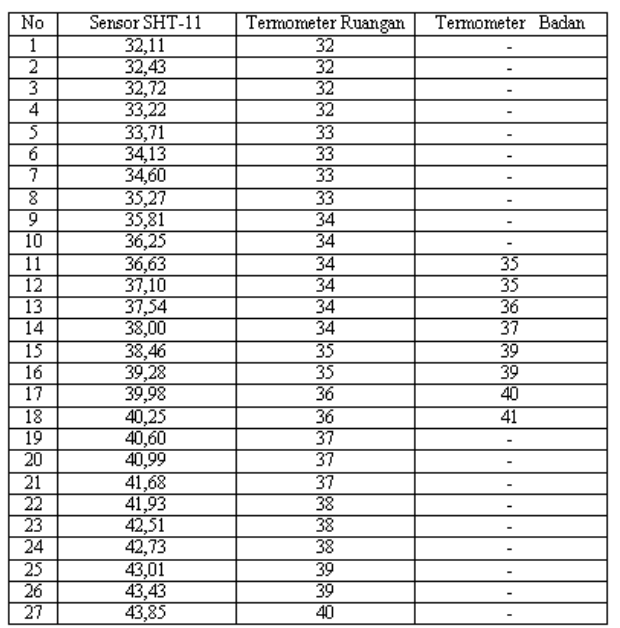

\subsubsection{Pengujian Sistem Keseluruhan}

Pada kondisi awal suhu $32,11^{\circ} \mathrm{C}$ dan kelembaban kurang lebih 79\% maka bagian-bagian yang aktif yaitu motor $\mathrm{AC}$, heater, blower.

Setelah SHT-11 membaca suhu pada kondisi $53^{\circ} \mathrm{C}$, maka blower dan heater serta motor $A C$ akan tetap bergerak selama 10 detik dibarengi dengan bunyi dari buzzer selama 3 detik yang menandakan bahwa kondisi $53^{\circ} \mathrm{C}$ telah tercapai.

Setelah 10 detik maka blower, heater akan mati dan motor tetap menyala dan pengkondisian akan dilakukan yaitu dengan mengecek apabila kelembaban mencapai 35\% maka yang akan aktif exhaust fan dan buzzer mati. Setelah 1 menit maka seluruh sistem akan dinonaktifkan.

Pengujian untuk tabel berikut selain menguji sistem secara keseluruhan, pengujian ini juga berguna untuk informasi tentang pengujian kelembaban ideal padi.
Tabel 6 Hasil pengujian sistem keseluruhan

\begin{tabular}{|c|c|c|c|c|c|c|c|c|}
\hline No. & Time & \multicolumn{2}{|c|}{ Input } & \multicolumn{5}{|c|}{ Output } \\
\cline { 3 - 9 } & $($ menit) & $\begin{array}{c}\text { Sulwu } \\
\left({ }^{\circ} \mathrm{C}\right)\end{array}$ & $\begin{array}{c}\mathrm{RH} \\
(\%)\end{array}$ & $\begin{array}{c}\text { Motor } \\
\mathrm{AC}\end{array}$ & Heater & Blower & Exhaust & Buzzer \\
\hline 1 & 10.00 & 40,11 & 60 & ON & ON & ON & OFF & OFF \\
\hline 2 & 20.00 & 46,88 & 49 & ON & ON & ON & OFF & OFF \\
\hline 3 & 30.00 & 50,49 & 42 & ON & ON & ON & OFF & OFF \\
\hline 4 & 40.00 & 53,00 & 36 & ON & ON & ON & OFF & ON \\
\hline 5 & 45.00 & 54,22 & 35 & OFF & OFF & OFF & ON & OFF \\
\hline
\end{tabular}

\subsubsection{Pengujian Kelembaban Padi}

Sampel yang diambil yaitu sebesar 500 gram atau $0,5 \mathrm{~kg}$ untuk setiap 10 menit selama 40 menit. Hasil perbandingan dari tabel 5 menunjukkan bahwa error perbandingan dari pengukuran dengan menggunakan SHT-11 dan Dole 400 cukup besar, sehingga SHT-11 dirasa belum cocok untuk tingkat pengukuran kadar air pada padi.

Dari hasil yang diperoleh diketahui bahwa tingkat kelembaban padi masih cukup tinggi untuk dikatakan ideal, karena padi yang ideal memiliki kelembaban sekitar 13-14 \%, oleh karena itu dibutuhkan waktu yang lebih untuk proses pengeringan.

Tabel 7 Perbandingan hasil kelembaban SHT-11 dengan Dole 400

\begin{tabular}{|c|c|c|c|c|c|}
\hline No & Sarmel & $\begin{array}{c}\text { Hasil } \\
\text { Kelembaban } \\
\text { (SHT-11) }\end{array}$ & $\begin{array}{c}\text { Hasil } \\
\text { Kelembaban } \\
\text { (Dole 400) }\end{array}$ & $\begin{array}{c}\text { Waktu } \\
\text { Pengambilan } \\
\text { (ment) }\end{array}$ & $\begin{array}{c}\text { Eror } \\
\text { Perbandingan }\end{array}$ \\
\hline 1 & 1 & $92 \%$ & $24,8 \%$ & 10.00 & $67,2 \%$ \\
\hline 2 & 2 & $91 \%$ & $24,2 \%$ & 20.00 & $66,8 \%$ \\
\hline 3 & 3 & $91 \%$ & $23,8 \%$ & 30.00 & $67,2 \%$ \\
\hline 4 & 4 & $90 \%$ & $22,2 \%$ & 40.00 & $67,8 \%$ \\
\hline
\end{tabular}

\section{SIMPULAN}

Pengujianprototypemenghasilkankualitaspadi yang tidak jauh berbeda dengan hasil pengeringan secara konvensional oleh petani, terlihat pada pengujian hasil padi dengan metode konvensional dan hasil padi dengan prototype pengering padi. Padi yang terlalu kering akan mengalami keretakan karena proses pengeringan yang tidak merata dan padi yang terlalu lembab akan rusak saat dilakukan proses pemisahan beras dan kulitnya. Disamping itu Minimum system dapat dikatakan bekerja dengan baik apabila menu sginature, open file, dan write dapat berhasil dikerjakan dan setiap tegangan 
keluaran yang dihasilkan tiap pin pada port-port berkisar antara $0 \mathrm{~V}$ sampai dengan $5 \mathrm{~V}$. Begitu pula dengan Pin-pin pada LCD yang digunakan adalah pin 4, 5, 6, 11, 12, 13, 14. Konfigurasi pinpin dengan mikrokontroler yang terhubung dengan baik akan memberikan informasi data yang baik pula. Pengujian sensor dengan mencocokkan nilai pada display LCD dengan termometer ruangan dan juga termometer badan sangat baik dilakukan untuk mengetahui perbandingan nilai antara pembacaan sensor SHT-11 dan juga termometer.

\section{KEPUSTAKAAN}

[1] Datasheet AT89S52, diakses 20 Desember 2009.URLwww.keil.com/dd/docs/datashts/ atmel/at89s52_ds.pdf.

[2] Datasheet SHT11, diakses 01 Oktober 2009 URLhttp://www.sensirion.com/en/pdf/ product_information/Datasheet-humiditysensor- SHT1x.pdf.

[3] Direktorat Pengolahan dan Pemasaran Hasil Tanaman Pangan, 2003, Teknologi Pengeringan Padi. Jakarta: Departemen Pertanian.

[4] Hartono, J, 2002, Konsep Dasar Pemrograman Bahasa $C$, Yogyakarta: ANDI.

[5] Nalwan, Paulus Andi, 2003, Panduan Praktis Teknik Antarmuka dan Pemrograman Mikrokontroler AT89C51, PT Elex Media Komputindo, Jakarta.

[6] Usman, 2008, Teknik Antarmuka + Pemrograman Mikrokontroler AT89S52, Yogyakarta: ANDI. 